\title{
El papel del aseguramiento en la protección social
}

\section{Daniel Titelman}

Experto en Políticas

Monetarias y Financieras,

Unidad de Estudios Especiales,

CEPAL

dtitelman@eclac.cl

\section{Andras Uthoff}

Coordinador,

Unidad de Estudios Especiales, CEPAL

authoff@eclac.cl
Los sistemas de protección social enfrentan serios descalces entre la necesidad y la disponibilidad de recursos financieros para cubrir las demandas. Por ello, tanto la contención de costos como la necesidad de aumentar la cobertura poblacional de los sistemas son elementos de cualquier propuesta de reforma. Para avanzar hacia la universalidad de los beneficios hay que fortalecer simultáneamente la eficiencia y la solidaridad. Una estrategia de reforma no sólo debe considerar las restricciones financieras impuestas desde la macroeconomía, sino también que el esquema elegido puede acarrear fuertes demandas de recursos financieros y afectar las cuentas fiscales, por el monto y volumen de los beneficios, la limitada capacidad de financiarlos mediante contribuciones y la necesidad de financiamiento solidario. Este artículo examina los diversos procesos de reformas al financiamiento de la seguridad social, que han implicado nuevas y diferentes combinaciones público-privadas. 


\section{I}

\section{Introducción}

Actualmente, las demandas de servicios de salud y de pensiones (y otros beneficios de la protección social) crecen a un ritmo que supera ampliamente la tasa de crecimiento efectiva del PIB o cualquier proyección de ella, por optimista que sea. Esto ha llevado a una creciente tensión entre las exigencias financieras de la seguridad social y la capacidad de los países de proveer los recursos demandados.

En este contexto, la reforma de los sistemas de protección social han pasado a ser parte integral de la agenda política de la mayoría de los países. En el ámbito regional, las necesidades de cambio se originan simultáneamente en dos aspectos. Por una parte, surgen de las falencias y dificultades que han mostrado los sistemas de protección social (seguro social y sector público) en el pasado y de los nuevos retos que imponen las dinámicas demográficas y epidemiológicas y el desarrollo tecnológico. Por la otra, se suman a estos desafíos de carácter interno aquellos derivados del proceso de globalización en que están encaminados los países de la región, el que ha afectado la naturaleza del sistema de protección y su capacidad de respuesta a las perturbaciones externas que enfrentan nuestras economías. En particular, la volatilidad financiera observada en la década de 1990 ha tenido importantes repercusiones sobre el ciclo económico de los países, lo que ha redundado en mayores riesgos sociales y en la necesidad de contar con mecanismos de protección social (Rodrik, 2001; CEPAL, 2001a). La adaptación de las empresas a la mayor inestabilidad económica ha descansado en ajustes laborales que han desembocado en una mayor precariedad del empleo nacional, lo que debilita la base contributiva de los sistemas de protección social. ${ }^{1}$

$\square$ Una versión de este trabajo fue presentada en el seminario "Política macroeconómica y vulnerabilidad social" (Santiago de Chile, 26 y 27 de noviembre de 2002), en el marco de un proyecto cofinanciado por el Departamento de Asuntos Económicos y Sociales de las Naciones Unidas y los gobiernos de Alemania y Francia. Los autores agradecen los comentarios de los participantes del seminario y, en especial, los formulados por Ricardo Ffrench-Davis, José Pablo Arellano y Oscar Altimir a un texto preliminar.

${ }^{1}$ Este trabajo examina, en particular, la forma cómo se cubren los riesgos de salud, vejez, invalidez y muerte. No trata los riesgos asociados al desempleo y la exclusión social, excepto cuando afectan la capacidad de las personas para participar en los sistemas de
Desde sus orígenes, los sistemas de protección social se han concebido como derechos sociales. Entre sus objetivos está el de combatir la pobreza, la discriminación y los riesgos sociales (Naciones Unidas, 2002). Las reformas que apuntan a modernizar esos sistemas aún deben superar tres desafíos históricos: i) universalizar la seguridad social; ii) disminuir las marcadas inequidades en el acceso a los servicios y en la calidad de los servicios que se ofrecen, y iii) mejorar la rentabilidad social de los recursos que se asignan a estas actividades, mediante cambios en su gestión y asignación. Las reformas deben estar encaminadas a fortalecer los sistemas de seguridad social para permitir la adecuación de la estructura de aseguramiento a las nuevas necesidades y realidades del proceso económico y social y, en particular, a la evolución observada en los mercados de trabajo.

En este artículo se argumenta que la existencia de mercados de trabajo heterogéneos y de entornos económicos volátiles e inciertos eleva los riesgos sociales. Los sistemas de seguridad social deben combinar esquemas de seguro y ahorro con redistribución y solidaridad. Puesto que el hecho de avanzar hacia una cobertura universal y beneficios garantizados se traduce en mayores demandas financieras al Estado, es preciso conciliar, a través de las reformas, las responsabilidades sociales y fiscales. Ejemplo de esas demandas es el surgimiento de pasivos contingentes que se generan en el sector público y para los cuales se requieren reglas de financiamiento en el tiempo (Arenas de Mesa y Guzmán, 2003). Una política macroeconómica destinada a apoyar las políticas sociales no sólo debe preocuparse por suavizar los ciclos económicos, sino que, además, debe generar reglas de gasto fiscal que permitan un gasto público contracíclico y compatible con los fundamentos de esa política. La forma en que se diseñe la combinación de sector público y sector privado influirá significativamente en la eficiencia y equidad del sistema de seguridad social y, por lo tanto, en las demandas que se planteen al fisco. En el caso

protección social contributivos. La tasa media de desempleo para América Latina aumentó más de cuatro puntos porcentuales en el decenio de 1990; según estimaciones de la CEPAL, siete de cada diez empleos fueron generados en el sector informal. 
de los sistemas de salud, una inadecuada combinación de los esfuerzos públicos y privados lleva a problemas de selección de riesgos y de exclusiones. En el caso de las pensiones, aunque se reconoce la importancia de sustituir los regímenes de beneficios definidos por otros de contribuciones definidas, el diseño de las opciones de reforma tiene un efecto considerable en los costos que debe asumir el fisco durante la transición y en las fuentes de financiamiento de las pen- siones solidarias para quienes carecen de capacidad contributiva.

Se examina también en el presente artículo el nuevo contexto en que deberán funcionar los sistemas de seguridad social, se pasa revista en particular a las reformas en materia de salud y pensiones que se han efectuado en países de la región y se analizan los desafíos de política surgidos de los procesos de reforma.

\section{II}

\section{Evolución del gasto público social}

Los países de la región realizan un esfuerzo nada despreciable en materia de gasto social. Como porcentaje del PIB, el gasto social pasó de 10,4\% en 1990-1991 a $14,1 \%$ en $2000-2001$, mostrando un comportamiento levemente contracíclico (cuadro 1). En cuanto al gasto en salud, el esfuerzo también es significativo. La región gasta en promedio entre 6 y 7 puntos del PIB, cifra bastante cercana al promedio mundial y no muy lejana de los 9 a 10 puntos de los países desarrollados. ${ }^{2}$

El aumento de casi cuatro puntos porcentuales adicionales del PIB destinados al gasto social debiera mejorar la cobertura de riesgos de la población y en particular de los más pobres. Sin embargo, no es obvio que así suceda mientras el gasto en sectores sociales no siempre se concentre en los sectores de menores ingresos (cuadro 2).

La experiencia de la región muestra que ha sido muy difícil focalizar el gasto social en los más pobres y/o en una mayor cobertura de la población. De ahí que los resultados de la política social no se condigan con los esfuerzos realizados en materia de gasto. Los sistemas de seguridad social (y de protección social en general) enfrentan simultáneamente un elevado crecimiento de la demanda de servicios y un alza de los costos de producirlos. Este aumento de las exigencias financieras se da en medio de una mayor volatilidad económica y de mayores restricciones fiscales en los países, de modo que las propuestas de reforma deben

\footnotetext{
${ }^{2}$ Aunque en cifras per cápita la diferencia es significativa: mientras los países desarrollados gastan casi 1.800 dólares per cápita por año, los países de la región gastan solamente 370. En general, los analistas encuentran dificultades para distinguir cuánto de este gasto se destina a inversiones y cuánto a gastos corrientes.
}

centrarse simultáneamente en mejorar aspectos de la eficiencia y la gestión para contener los costos y, dado lo precario de los ingresos de gran parte de la población, en fortalecer los mecanismos de solidaridad.

Entre los factores que determinan la demanda de servicios de seguridad social se pueden distinguir los relacionados con el ciclo económico y los que dependen de factores más bien estructurales. Los primeros están estrechamente vinculados con el ritmo de crecimiento de la economía y las políticas macroeconómicas y sociales. Los segundos, reflejan aspectos demográficos, epidemiológicos y tecnológicos.

Una de las vías principales por la cual el ciclo económico afecta los sistemas de seguridad social es su impacto en el mercado de trabajo. Mientras los sistemas de seguridad social en los países de América Latina sigan el modelo bismarckiano, el acceso a los sistemas de protección social estará condicionado por la relación contractual del trabajador, de modo que los esquemas de contribuciones dependerán de la dinámica del mercado de trabajo. Los cambios que se producen en este último afectan no sólo las demandas de servicios sociales, sino también las fuentes de financiamiento para satisfacer esas demandas. Por ejemplo, el hecho de que una mayoría laboral se mueva en el ámbito de la informalidad ha impuesto límites, en los esquemas actuales, a la universalización de la seguridad social y a la capacidad de recurrir a las contribuciones salariales como principal fuente de financiamiento.

La evolución del mercado de trabajo en los países latinoamericanos en el decenio de 1990 y los dos primeros años de la década de 2000 no ha sido favorable. Ha estado marcada por la forma en que las economías se han ajustado a las perturbaciones externas 
CUADRO 1

América Latina: Gasto público social total

(Porcentaje del PIB)

\begin{tabular}{|c|c|c|c|c|c|c|}
\hline & 1990-1991 & 1992-1993 & 1994-1995 & 1996-1997 & 1998-1999 & 2000-2001 \\
\hline América Latina & 10,4 & 11,3 & 12,0 & 12,3 & 13,1 & 14,1 \\
\hline Argentina & 19,3 & 20,1 & 21,1 & 20,0 & 20,8 & 21,6 \\
\hline Bolivia & $\ldots$ & & 12,4 & 1,6 & 16,3 & 17,9 \\
\hline Brasil & 18,1 & 17,7 & 19,3 & 17,3 & 19,3 & 18,8 \\
\hline Chile & 11,7 & 12,4 & 12,3 & 13,0 & 14,7 & 16,0 \\
\hline Colombia & 6,8 & 8,1 & 11,5 & 15,3 & 14,0 & 13,6 \\
\hline Costa Rica & 15,6 & 15,2 & 15,8 & 16,8 & 16,4 & 18,2 \\
\hline Ecuador & 5,5 & 5,8 & 7,4 & 8,2 & 8,1 & 8,8 \\
\hline El Salvador & $\ldots$ & 3,1 & 3,4 & 3,8 & 4,1 & 4,2 \\
\hline Guatemala & 3,4 & 4,1 & 4,1 & 4,3 & 6,0 & 6,2 \\
\hline Honduras & 7,9 & 8,1 & 7,8 & 7,2 & 7,5 & 10,0 \\
\hline México & 6,5 & 8,1 & 8,8 & 8,5 & 9,2 & 9,8 \\
\hline Nicaragua & 11,1 & 10,9 & 12,2 & 11,3 & 13,0 & 13,2 \\
\hline Panamá & 18,6 & 19,5 & 19,8 & 20,9 & 21,6 & 25,5 \\
\hline Paraguay & 3,1 & 6,2 & 7,0 & 8,0 & 8,5 & 8,5 \\
\hline Perú & 4,0 & 5,3 & 6,7 & 7,1 & 7,7 & 8,0 \\
\hline R. Dominicana & 4,3 & 5,9 & 6,1 & 6,0 & 6,6 & 7,6 \\
\hline Uruguay & 16,9 & 18,9 & 20,3 & 21,3 & 22,8 & 23,5 \\
\hline Venezuela & 8,5 & 8,9 & 7,6 & 8,3 & 8,4 & 11,3 \\
\hline
\end{tabular}

Fuente: CEPAL, sobre la base de cifras oficiales.

CUADRO 2

América Latina: Variación del gasto social per cápita y porcentaje destinado al primer quintila

(Porcentajes)

\begin{tabular}{|c|c|c|c|c|c|c|c|c|}
\hline \multirow[t]{2}{*}{ Países } & \multicolumn{2}{|c|}{ Educación } & \multicolumn{2}{|c|}{ Salud y nutrición } & \multicolumn{2}{|c|}{ Seguridad social } & \multicolumn{2}{|c|}{ Vivienda, agua, sanidad y otros } \\
\hline & $\begin{array}{c}\text { Aumento } \\
\text { porcentual } \\
\text { en la década }\end{array}$ & $\begin{array}{c}\text { Porcentaje } \\
\text { destinado al } \\
20 \% \text { más pobre }\end{array}$ & $\begin{array}{c}\text { Aumento } \\
\text { porcentual } \\
\text { en la década }\end{array}$ & $\begin{array}{c}\text { Porcentaje } \\
\text { destinado al } \\
20 \% \text { más pobre }\end{array}$ & $\begin{array}{c}\text { Aumento } \\
\text { porcentual } \\
\text { en la década }\end{array}$ & $\begin{array}{c}\text { Porcentaje } \\
\text { destinado al } \\
20 \% \text { más pobre }\end{array}$ & $\begin{array}{c}\text { Aumento } \\
\text { porcentual } \\
\text { en la década }\end{array}$ & $\begin{array}{c}\text { Porcentaje } \\
\text { destinado al } \\
20 \% \text { más pobre }\end{array}$ \\
\hline Promedio & 37,2 & 27,9 & 25,2 & 26,9 & 37,4 & 15,0 & 20,4 & 22,1 \\
\hline Argentina & 41,0 & 32,5 & 28,7 & 38,7 & 20,9 & 11,0 & 30,1 & 20,5 \\
\hline Brasil $^{\mathrm{b}}$ & 13,9 & 30,1 & 4,9 & 31,5 & 36,6 & 42,0 & $-10,3$ & 30,8 \\
\hline Chile & 56,9 & 34,0 & 52,4 & 30,9 & 39,5 & 4,0 & 48,9 & 37,3 \\
\hline Colombia & 48,3 & 21,4 & 77,9 & 17,5 & 54,5 & $\ldots$ & 53,8 & $\ldots$ \\
\hline Costa Rica & 29,4 & 15,7 & 17,1 & 2,7 & 31,5 & 7,1 & 1,6 & $\ldots$ \\
\hline Guatemala & 40,0 & $\ldots$ & 36,4 & $\ldots$ & 25,0 & $\ldots$ & 93,3 & $\ldots$ \\
\hline Honduras & $-3,1$ & $\ldots$ & $-25,0$ & $\ldots$ & $\ldots$ & $\ldots$ & 40,0 & $\ldots$ \\
\hline México & 37,7 & $\ldots$ & $-28,0$ & $\ldots$ & 89,3 & $\ldots$ & 35,0 & $\ldots$ \\
\hline Nicaragua & 15,4 & $\ldots$ & 0,0 & $\ldots$ & $\ldots$ & $\ldots$ & 50,0 & $\ldots$ \\
\hline Panamá & 36,9 & $\ldots$ & 2,6 & $\ldots$ & 13,4 & $\ldots$ & $-26,2$ & $\ldots$ \\
\hline Paraguay & 66,7 & $\ldots$ & 73,7 & $\ldots$ & 54,3 & $\ldots$ & $-300,0$ & $\ldots$ \\
\hline Perú & 54,8 & $\ldots$ & 60,5 & $\ldots$ & 71,3 & $\ldots$ & 78,6 & $\ldots$ \\
\hline R. Dominicana & 70,2 & $\ldots$ & 51,6 & $\ldots$ & 62,5 & $\ldots$ & 16,1 & $\ldots$ \\
\hline Uruguay & 40,4 & 33,2 & 18,2 & 34,9 & 46,4 & 12,4 & 51,5 & 14,1 \\
\hline Venezuela & 7,9 & $\ldots$ & $-16,3$ & $\ldots$ & 5,3 & $\ldots$ & $-100,0$ & $\ldots$ \\
\hline
\end{tabular}

Fuente: CEPAL (2001b), cuadros IV. 5 y IV.7.

a Los aumentos porcentuales son estimados con relación al valor al final del período.

b Las cifras de educación incluyen sólo la primaria. En seguridad social sólo se incluyen pensiones. La estimación es para el gasto social consolidado. 
CUADRO 3

América Latina y el Caribe: Desempleo urbano ${ }^{a}$

(Tasas medias anuales)

\begin{tabular}{|c|c|c|c|c|c|c|c|c|c|c|c|c|}
\hline & Área & 1990 & 1993 & 1994 & 1995 & 1996 & 1997 & 1998 & 1999 & 2000 & 2001 & 2002 \\
\hline $\begin{array}{l}\text { América Latina y } \\
\text { el Caribe }\end{array}$ & & 5,8 & 6,6 & 6,6 & 7,5 & 8,0 & 7,6 & 8,1 & 8,9 & 8,4 & 8,4 & 9,0 \\
\hline $\begin{array}{l}\text { Promedio simple } \\
\text { de } 22 \text { países }\end{array}$ & & $\ldots$ & 10,0 & 9,5 & 10,1 & 10,5 & 9,9 & 9,7 & 10,3 & 10,1 & 10,3 & \\
\hline \multicolumn{13}{|l|}{ América Latina } \\
\hline Bolivia & $\mathrm{CD}$ & 7,3 & 5,8 & 3,1 & 3,6 & 3,8 & 4,4 & 6,1 & 8,0 & 7,5 & 8,5 & \\
\hline Brasil & $6 \mathrm{AM}$ & 4,3 & 5,4 & 5,1 & 4,6 & 5,4 & 5,7 & 7,6 & 7,6 & 7,1 & 6,2 & 7,1 \\
\hline Chile & $\mathrm{TN}$ & 7,8 & 6,5 & 7,8 & 7,4 & 6,4 & 6,1 & 6,4 & 9,8 & 9,2 & 9,1 & 9,0 \\
\hline Colombia & 7AM & 10,5 & 8,6 & 8,9 & 8,8 & 11,2 & 12,4 & 15,3 & 19,4 & 17,2 & 18,2 & 17,6 \\
\hline Costa Rica & $\mathrm{TU}$ & 5,4 & 4,0 & 4,3 & 5,7 & 6,6 & 5,9 & 5,4 & 6,2 & 5,3 & 5,8 & 6,8 \\
\hline Cuba & $\mathrm{TN}$ & $\ldots$ & 6,2 & 6,7 & 7,9 & 7,6 & 7,0 & 6,6 & 6,0 & 5,5 & 4,1 & 3,5 \\
\hline Ecuador & $\mathrm{TU}$ & 6,1 & 8,9 & 7,8 & 7,7 & 10,4 & 9,3 & 11,5 & 15,1 & 14,1 & 10,4 & 8,6 \\
\hline Guatemala & $\mathrm{TN}$ & 6,3 & 2,6 & 3,5 & 3,9 & 5,2 & 5,1 & 3,8 & $\ldots$ & $\ldots$ & $\ldots$ & $\ldots$ \\
\hline Honduras & $\mathrm{TU}$ & 7,8 & 7,0 & 4,0 & 5,6 & 6,5 & 5,8 & 5,2 & 5,3 & $\ldots$ & 6,3 & 6,2 \\
\hline México & $\mathrm{AU}$ & 2,7 & 3,4 & 3,7 & 6,2 & 5,5 & 3,7 & 3,2 & 2,5 & 2,2 & 2,5 & 2,7 \\
\hline Nicaragua & $\mathrm{TN}$ & 7,6 & 17,8 & 17,1 & 16,9 & 16,0 & 14,3 & 13,2 & 10,7 & 9,8 & 10,7 & 12,9 \\
\hline Panamá & $\mathrm{RM}$ & 20,0 & 15,6 & 16,0 & 16,6 & 16,9 & 15,5 & 15,2 & 14,0 & 15,2 & 16,9 & 16,1 \\
\hline Paraguay & $\mathrm{TU}$ & 6,6 & 5,1 & 4,4 & 5,3 & 8,2 & 7,1 & 6,6 & 9,4 & 10,0 & 10,8 & $\ldots$ \\
\hline Perú & LM & 8,3 & 9,9 & 8,8 & 8,2 & 8,0 & 9,2 & 8,5 & 9,2 & 8,5 & 9,3 & 9,4 \\
\hline R. Dominicana & $\mathrm{TN}$ & $\ldots$ & 19,9 & 16,0 & 15,8 & 16,5 & 15,9 & 14,3 & 13,8 & 13,9 & 15,6 & 16,1 \\
\hline Uruguay & TU & 8,5 & 8,3 & 9,2 & 10,3 & 11,9 & 11,5 & 10,1 & 11,3 & 13,6 & 15,3 & 17,0 \\
\hline Venezuela & $\mathrm{TN}$ & 10,4 & 6,6 & 8,7 & 10,3 & 11,8 & 11,4 & 11,3 & 14,9 & 14,0 & 13,4 & 15,9 \\
\hline \multicolumn{13}{|l|}{ Caribe } \\
\hline Barbados & $\mathrm{TN}$ & 14,7 & 24,3 & 21,9 & 19,7 & 15,6 & 14,5 & 12,3 & 10,4 & 9,2 & 9,9 & 10,5 \\
\hline Jamaica & $\mathrm{TN}$ & 15,3 & 16,3 & 15,4 & 16,2 & 16,0 & 16,5 & 15,5 & 15,7 & 15,5 & 15,0 & $\ldots$ \\
\hline Trinidad y Tabago & $\mathrm{TN}$ & 20,1 & 19,8 & 18,4 & 17,2 & 16,2 & 15,0 & 14,2 & 13,1 & 12,8 & 11,1 & 11,0 \\
\hline
\end{tabular}

Fuente: CEPAL (2002a).

a AU: áreas urbanas; TN: total nacional; CD: capitales departamentales; AM: áreas metropolitanas; TU: total urbano; LM: Lima metropolitana; RM: región metropolitana. Los promedios simples de 1999, 2000 y 2001 están ajustados por compensación de datos faltantes. Las cifras del total de América Latina para el primer semestre de 2001 y 2002 son promedios ponderados de los países que disponen de la información.

y por la debilidad y volatilidad de la tasa de crecimiento, lo que ha dificultado la generación de empleo para una población económicamente activa que crece por la inercia demográfica y por la mayor integración de la mujer a la fuerza de trabajo. De hecho, la política macroeconómica de la mayoría de los países de la región ha mostrado un fuerte comportamiento procíclico y un menoscabo de la capacidad de utilizar instrumentos fiscales, monetarios y cambiarios para ajustarse a perturbaciones externas reales o financieras. Por ello, el peso del ajuste ha recaído de manera creciente en los mercados de trabajo a través de niveles más altos de desempleo y trabajo informal. Ha aumentado así la vulnerabilidad al desempleo, se ha incrementado también la rotación en el empleo (una característica del empleo privado), y una mayor proporción de trabajado- res está sin cobertura de riesgos, ya que muchos empleos son precarios y sin acceso a la protección social. ${ }^{3}$

La tasa media de desempleo en la región mostró una tendencia ascendente en el decenio de 1990 y alcanzó un máximo de 9,0\% en 2002. Asimismo, la elasticidad empleo-producto ha tendido a caer, con lo cual se requieren mayores tasas de crecimiento para

\footnotetext{
3 Tokman (2003) destaca tres factores que contribuyeron a que el ajuste recayera en el mercado de trabajo: i) las reformas introducidas para ampliar las causales de despido y reducir los tiempos de ajuste de las empresas, acentuada por asimetrías que hacen incidir en el empleo gran parte del peso del ajuste económico; ii) los procesos de privatización, que han contribuido a trasladar la generación de empleo desde el sector público al privado, y iii) los cambios en la estructura del empleo privado en favor de ocupaciones informales, terciarias y sin contrato o protección social.
} 
generar más puestos de trabajo. Junto con caer la elasticidad, ha aumentado la "precarización" del mercado de trabajo con la importancia creciente del empleo informal (cuadro 4). Según estimaciones de la Organización Internacional del Trabajo (OIT), en la década de 1990 siete de cada diez empleos fueron generados en el sector informal.

Lo anterior significa que los seguros de desempleo desempeñarán un papel importante en el futuro, no sólo como estabilizadores del ingreso interno, sino también como fuente importante de cualquier esquema de seguridad social. ${ }^{4}$

Un elemento no menor que afecta el mercado laboral y el diseño de los sistemas de seguridad social es la exigencia de mayor competitividad y de cambios tecnológicos que genera el proceso de inserción internacional. La necesidad de adaptar la estructura productiva al contexto de economías abiertas al exterior obliga a introducir más movilidad laboral entre distintos sectores productivos para adaptarse a las nuevas necesidades de la producción.

Si bien son deseables, la mayor movilidad laboral entre sectores y el aumento de la competitividad no

CUADRO 4

\section{América Latina: Estructura del empleo no agrícola (Porcentajes)}

\begin{tabular}{lccccc}
\hline & & \multicolumn{4}{c}{ Ocupados } \\
\cline { 3 - 6 } & Total & Sector informal & \multicolumn{2}{c}{ Sector formal } \\
& & 1990 & 2001 & 1990 & 2001 \\
\hline América Latina & 100 & 42,8 & 46,3 & 57,2 & 53,7 \\
Argentina & 100 & 52,0 & 45,7 & 48,0 & 54,3 \\
Brasil & 100 & 40,6 & 46,0 & 59,4 & 54,0 \\
Chile & 100 & 37,9 & $38,0^{\mathrm{a}}$ & 62,1 & $62,0^{\mathrm{a}}$ \\
Colombia & 100 & 45,7 & 55,6 & 54,3 & 44,4 \\
Costa Rica & 100 & 41,2 & 44,9 & 58,8 & 55,1 \\
Ecuador & 100 & 55,6 & 57,4 & 44,4 & 42,6 \\
Honduras & 100 & 57,6 & $60,7^{\mathrm{b}}$ & 42,4 & $39,2^{\mathrm{b}}$ \\
México & 100 & 38,4 & 39,6 & 61,6 & 60,4 \\
Panamá & 100 & 36,0 & $37,3^{\mathrm{a}}$ & 64,0 & $62,7^{\mathrm{a}}$ \\
Perú & 100 & 52,7 & 59,5 & 47,3 & 40,5 \\
Uruguay & 100 & 39,1 & 42,2 & 60,9 & 57,8 \\
Venezuela & 100 & 38,6 & 49,2 & 61,4 & 50,8 \\
\hline
\end{tabular}

Fuente: OIT (2002).

a Corresponde a 2000.

b Corresponde a 1999.

\footnotetext{
${ }^{4}$ En este trabajo no nos ocupamos del riesgo del desempleo, excepto en cuanto limita la ampliación de la cobertura de la protección social. Véase un análisis actual acerca de los seguros de desempleo en Velásquez (2003).
}

deben lograrse a expensas de la seguridad social. Por el contrario, un desafío de las reformas es compatibilizar los mecanismos y costos de aseguramiento con las necesidades de movilidad laboral y de competitividad. En la medida en que los sistemas de protección social faciliten la movilidad laboral entre sectores de producción competitivos contribuirán a mejorar la capacidad del mercado laboral para responder a perturbaciones externas. Para ello se precisan beneficios de la seguridad social (particularmente en materia de salud y pensiones) que sean portables y se financien a partir de activos adquiridos a costos competitivos.

La mayor volatilidad observada en el ciclo económico ha traído aparejada más inestabilidad en los niveles de ingreso, lo que se traduce en un mayor riesgo social y económico. Esto ha significado tanto una menor capacidad contributiva como una mayor demanda de seguros y protección social. En estas circunstancias, los sistemas de seguridad social deben conciliar las funciones de aseguramiento, para enfrentar el aumento de los riesgos económicos con las funciones distributivas, y de solidaridad, para poder proporcionar una cobertura universal ante dichos riesgos.

Es aquí donde el nivel y la composición del gasto público, en particular en el campo de la protección social, pueden servir para estabilizar el nivel de ingreso interno y de esta manera transformarse en un seguro contra los riesgos sociales en economías expuestas a fuertes y frecuentes perturbaciones externas. Al respecto, Rodrik (1998) muestra una correlación positiva entre el grado de integración de una economía con el mundo y el tamaño del Estado. Esto es, a mayores niveles de apertura externa se detecta mayor gasto público, ya sea en consumo o en seguridad social. ${ }^{5}$

Entre los principales avances en aspectos macroeconómicos durante el decenio de 1990 destacan la consolidación de las cuentas fiscales y la caída de la tasa de inflación. En materia de ajuste fiscal, el déficit se mantuvo la mayor parte de la década, en promedio, alrededor del 1,6\% del PIB, aunque durante la crisis reciente (1997-2002), cuando se hicieron evidentes los graves problemas fiscales de algunos países, llegó a cifras superiores al 3\% del PIB. El mantenimiento de niveles moderados de déficit fiscal ha sido consistente, sin embargo, con una recuperación de los niveles de gasto público (cuadros 1 y 5).

A pesar de los logros en materia fiscal, el manejo procíclico de la política tributaria ha afectado negativamente la capacidad de financiar los servicios de se-

\footnotetext{
${ }^{5}$ El grado de apertura económica se mide por el coeficiente de exportaciones e importaciones respecto del PIB.
} 


\begin{tabular}{|c|c|c|c|c|c|c|c|c|c|c|c|}
\hline & 1992 & 1993 & 1994 & 1995 & 1996 & 1997 & 1998 & 1999 & 2000 & 2001 & 2002 \\
\hline $\begin{array}{l}\text { Producto interno bruto } \\
\quad \text { (tasas anuales de variación) }\end{array}$ & 3,0 & 3,3 & 5,2 & 1,1 & 3,7 & 5,1 & 2,2 & 0,5 & 3,8 & 0,3 & $-0,5$ \\
\hline $\begin{array}{l}\text { Resultado del sector público } \\
\text { (\% del PIB })\end{array}$ & $-1,4$ & $-1,4$ & $-1,8$ & $-1,5$ & $-1,5$ & $-1,4$ & $-2,4$ & $-2,8$ & $-2,5$ & $-3,2$ & $-3,3$ \\
\hline $\begin{array}{l}\text { Indice de precios al } \\
\text { consumidor (variación } \\
\text { diciembre a diciembre) }\end{array}$ & 414,4 & $\begin{array}{c}872,4 \\
(898,3)\end{array}$ & $\begin{array}{c}328,7 \\
(340,9)\end{array}$ & $\begin{array}{c}26,0 \\
(25,9)\end{array}$ & $\begin{array}{c}18,6 \\
(18,6)\end{array}$ & $\begin{array}{c}10,7 \\
(10,3)\end{array}$ & $\begin{array}{l}10,0 \\
(9,8)\end{array}$ & $\begin{array}{c}9,7 \\
(9,5)\end{array}$ & $\begin{array}{c}9,0 \\
(8,6)\end{array}$ & $\begin{array}{c}6,1 \\
(5,9)\end{array}$ & $\begin{array}{c}11,4 \\
(12,2)\end{array}$ \\
\hline $\begin{array}{l}\text { Gasto público total, en } \\
\text { porcentaje del PIB }\end{array}$ & 17,5 & 17,8 & 18,0 & 18,2 & 18,1 & 18,6 & 19,3 & 20,5 & 20,6 & 19,8 & $\cdots$ \\
\hline $\begin{array}{l}\text { Gasto público social, en } \\
\text { porcentaje del PIB }\end{array}$ & 10,9 & 11,9 & 12,1 & 12,1 & 12,4 & 12,5 & 12,7 & 13,4 & $\cdots$ & $\cdots$ & $\ldots$ \\
\hline
\end{tabular}

Fuente: CEPAL (2002b), y para las cifras entre paréntesis, CEPAL (2003).

guridad social cuando la demanda de ellos ha aumentado en períodos recesivos. La evolución del gasto social ha seguido los vaivenes del crecimiento económico, lo que significa que durante las fases descendentes del ciclo la menor disponibilidad de ingresos ha impedido la expansión (o mantención) de la cobertura mediante mayor gasto fiscal. De ahí que una política macroeconómica que apoye a la política de protección social no sólo debe preocuparse por suavizar los ciclos económicos sino que debe, además, generar reglas de gasto fiscal que permitan un gasto público contracíclico. En tal sentido, las normas que tienden a vincular las metas fiscales en función de parámetros estructurales y no coyunturales son un elemento importante de las políticas sociales. Esto es particularmente válido en el nuevo escenario de vulnerabilidad y volatilidad en que se mueven las economías latinoamericanas.

Cabe consignar que en términos de protección social se anticipan cambios estructurales que ocurren en forma independiente del ciclo económico y que hacen prever aumentos sustantivos en las demandas de servicios sociales. Destacan entre ellos el envejecimiento de la población, los cambios en las características epidemiológicas, los cambios tecnológicos (en particular en el área de la salud) y los cambios en las estructuras de los hogares.

\section{III}

\section{Reformas en materia de salud y pensiones}

Es común que los sistemas de protección social enfrenten serios descalces entre las necesidades de recursos financieros y la disponibilidad de esos recursos para satisfacer las demandas. Esto hace que la contención de costos sea un elemento central de cualquier propuesta de reforma a los sistemas, incluso en economías industrializadas que parten de una protección social con cobertura universal. En América Latina la situación es más grave, por cuanto la contención de costos no es el único desafío que encaran las reformas. La necesidad de incluir segmentos significativos de la población en los sistemas de seguridad social hace imprescindible avanzar hacia la universalidad de los beneficios. Por lo tanto, la eficiencia y la solidaridad son elementos constitutivos de una agenda de reforma.
De ahí la importancia que en las reformas latinoamericanas adquiere el modo en que se articulen el financiamiento y la provisión de beneficios. Este afectará no sólo el funcionamiento de los sistemas de salud y de pensiones, sino que, al intentar extender la cobertura hacia sectores que carecen de capacidad contributiva, tendrá además un importante efecto sobre las finanzas públicas. Por esto, una estrategia de reforma no sólo debe considerar las restricciones financieras impuestas desde la macroeconomía, sino también el hecho de que el diseño que se lleve a la práctica puede tener fuertes repercusiones sobre las demandas de recursos financieros y, por ende, sobre las cuentas fiscales.

Esto último es de vital importancia, ya que en la mayoría de los países de la región las reformas 
contemplan importantes cambios en la combinación del esfuerzo público y el privado, a través de una mayor participación del sector privado en la gestión del financiamiento de los regímenes contributivos y de la provisión de los servicios. La forma en que se configura la combinación del sector público y el privado en los sistemas de seguridad social afecta la función distributiva del Estado. Por esto, para alcanzar objetivos de equidad, solidaridad y eficiencia se requiere mejorar las instituciones existentes y/o crear instituciones adicionales, lo que repercutirá de manera significativa en las necesidades financieras del sector público.

\section{Las reformas al financiamiento de los sistemas de salud}

\section{a) Organización del financiamiento}

En el caso de los sistemas de salud, la evidencia internacional muestra que gastar más no siempre asegura mejores resultados. Estados Unidos gasta por este concepto alrededor de $13 \%$ del PIB y su cobertura poblacional e indicadores de salud están por debajo de aquellos de los demás países de la Organización de Cooperación y Desarrollo Económicos (OCDE), que gastan en promedio alrededor de $8 \%$ a $9 \%$ del PIB. Esto sugiere que la forma en que se organiza la estructura de financiamiento y provisión de servicios del sector salud influye fuertemente en las demandas de recursos del sector y en los resultados que se obtengan (White, 1995).

Por este motivo, uno de los principales desafíos que han enfrentado las reformas ha sido el de establecer las reglas y organización institucional del financiamiento y la forma de articularlo con la provisión de servicios (Londoño y Frenk, 1997). En general, se ha ido ganando consenso sobre las ventajas de separar las funciones de financiamiento y provisión de servicios. Respecto a la función financiera $-\mathrm{y}$ dado que el entorno económico es cada vez más incierto y la demanda de servicios de salud tiene un importante componente aleatorio caracterizado por la incertidumbre y la diversidad de riesgos-, los seguros sociales se han convertido en una forma eficiente de organizar el financiamiento del sector salud (Buti, Franco y Pench, 2000).

Un seguro social de salud debe conciliar las funciones de aseguramiento con las de solidaridad, distribución y cobertura universal, y debe hacerlo con independencia de la inserción laboral de las personas. Para ello es preciso definir reglas sobre la prima del seguro, las fuentes de financiamiento, el grado y nivel de beneficios y cobertura que ofrece, el universo poblacional al cual cobija y los criterios de elegibilidad. La forma como se resuelva todo esto afectará significativamente el monto del financiamiento que el sector salud requerirá del resto de la sociedad; el grado en que se integrarán las funciones de aseguramiento y de solidaridad, y los rasgos que adoptará la dinámica público-privada en la gestión financiera y la provisión de servicios.

En un contexto de seguros sociales, independientemente de si son gestionados por administradores públicos y/o privados, tienen que conciliarse las funciones de aseguramiento con las de distribución para poder avanzar hacia la universalidad de la cobertura. ${ }^{6} \mathrm{El}$ costo de la prima por afiliado no debe basarse en riesgos que reflejen factores individuales (como edad, sexo, o historial médico), sino en riesgos colectivos que consideren al conjunto de la población. Esto lleva a establecer subsidios para cubrir el costo de las primas, con miras a que las personas puedan acceder a los beneficios ofrecidos por los seguros, cualesquiera sean sus riesgos individuales y su capacidad de pago. De esa manera se incorpora la solidaridad entre sanos y enfermos, entre jóvenes y viejos, y entre altos y bajos ingresos.

Desde esta perspectiva, el gasto privado en salud no debe confundirse con la administración privada de dineros del sistema de seguridad social, que se refiere a la gestión privada de dineros públicos. El gasto privado en salud es aquel gasto que se hace por fuera de la cobertura del sistema de seguridad social (los llamados gasto de bolsillo, copagos, etc.). El que este gasto privado sea un componente importante del gasto total en salud refleja la debilidad de los sistemas sociales de protección. Mientras mayor es la participación del gasto privado en el total del gasto en salud, más excluyentes e inequitativos son los sistemas de salud (oms, 2000).

$\mathrm{Al}$ comparar la estructura del gasto en salud de los países latinoamericanos con la de los países industrializados se observa que en estos últimos la participación del gasto público es mucho mayor, lo que refleja el hecho de que su sistema de protección social en salud tiene cobertura universal e integral. En América Latina y el Caribe, en cambio, el gasto privado en salud en 1995 giraba en torno al 60\% del gasto total en salud (cuadros 6 y 7).

\footnotetext{
${ }^{6}$ A través de prestaciones que no necesariamente deben ser públicas, y bien pueden ser provistas por operadores privados.
} 
CUADRO 6

Algunas regiones y países: Gasto público en salud, 1995

\begin{tabular}{lrrr}
\hline & $\begin{array}{c}\text { Gasto per cápita } \\
\text { (dólares) }^{\mathrm{a}}\end{array}$ & & \multicolumn{2}{c}{ Como porcentaje } \\
\cline { 4 - 5 } & & & $\begin{array}{c}\text { Del PIB } \\
\text { total en sasto }\end{array}$ \\
\hline América Latina y el Caribe & 102 & 3,0 & 41,5 \\
Canadá & 1314 & 7,0 & 71,0 \\
OCDE & 1310 & 6,6 & 76,2 \\
Estados Unidos & 1628 & 6,3 & 44,0 \\
\hline
\end{tabular}

Fuente: Datos de la Organización Mundial de la Salud (OMS).

a En paridad de poder de compra.

\section{b) Solidaridad en el financiamiento}

Avanzar hacia una mayor cobertura poblacional implica aumentar el monto de subsidios que se destinan al sector, lo que redunda en una mayor demanda de recursos financieros. Fortalecer la protección social en salud implica acrecentar la eficiencia, tanto en la asignación y gestión de los recursos para mejorar los servicios como en los mecanismos de solidaridad vinculados a los ingresos, en particular los subsidios cruzados desde los sectores de altos ingresos hacia los de ingresos bajos. Mientras las mejoras de eficiencia reducen costos y ayudan a aminorar la demanda de recursos financieros, los mecanismos de solidaridad tienden a elevar los costos pero permiten incorporar más población a los beneficios de la seguridad social (Van de Ven y Van Vliet, 1992).

La solidaridad en materia de ingresos en un contexto de seguro social de riesgos se introduce mediante la creación de fondos de solidaridad encargados de distribuir subsidios que compensen los diferentes riesgos individuales (gráfico 1). Cada individuo contribuye en función de su ingreso. El valor de la prima se fija en función del riesgo y el costo medio, y las agencias aseguradoras reciben pagos en función de su cartera de riesgos. Este sistema implica que, dependiendo de los niveles de ingresos y de riesgos, hay personas que contribuyen más que el valor medio de las primas y personas que contribuyen menos que ese valor. El mayor aporte de las primeras, unido a la recaudación de otros impuestos, proveen los recursos del fondo de solidaridad.

Este mecanismo permite, en un contexto de seguros de riesgos, mantener el principio de equivalencia entre contribuciones y beneficios a nivel agregado del seguro, pero introduce solidaridad en la medida que el asegurado recibe un paquete de beneficios independiente de su contribución individual: si el nivel de gasto
CUADRO 7

América Latina y el Caribe: Composición del gasto total (público y privado) en salud, por subsectores, 1990 y 1995 (Como porcentaje del gasto total)

\begin{tabular}{llrr}
\hline & & \multicolumn{2}{c}{ Gasto en salud } \\
\cline { 3 - 4 } & Subsector & 1990 & 1995 \\
\hline Gasto público & & 43,4 & 41,5 \\
Gobierno central & & 12,2 & 15,8 \\
Gobierno local & & 7,4 & 8,5 \\
& Seguridad social & 23,8 & 17,2 \\
Gasto privado & & 56,6 & 59,5 \\
& Directo & $\ldots$ & 39,0 \\
Total & Indirecto & $\ldots$ & 19,5 \\
& & 100,0 & 100,0 \\
\hline
\end{tabular}

Fuente: Molina, Pinto y otros (2000): para 1990, sobre la base de Suárez y otros (1995); para 1995, sobre la base de OPS/OMS (1998), cuadro 54.

GRAFICO 1

Solidaridad en un contexto de seguros

Transformar

Contribuciones basadas en ingresos en pagos ajustados por riesgo $\mathrm{C}=$ Cotizaciones $/ \mathrm{AS}=$ Agencia Aseguradora

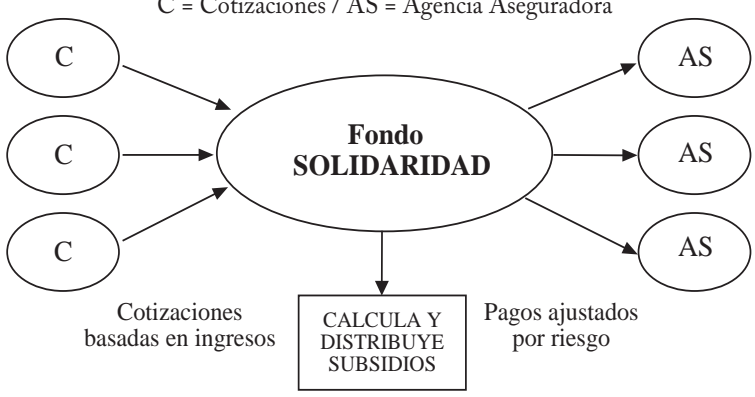

Fuente: Adaptado de Titelman y Uthoff (2000).

esperado del usuario supera el gasto promedio, el mayor desembolso será cubierto sobre la base de los subsidios. Este sistema desincentiva además la selección de riesgos, ya que si bien los asegurados pagan según sus capacidades, las aseguradoras reciben ingresos en función de sus carteras de riesgo, lo que en última instancia determina el gasto esperado. ${ }^{7}$

El grado de cobertura poblacional del seguro social está también estrechamente ligado a la procedencia del financiamiento. Cuando los seguros se financian exclusivamente a partir de aportes salariales (que

\footnotetext{
7 En la región, la reforma colombiana incorpora este tipo de fondos. La discusión actual de la reforma chilena contempla la creación de un fondo solidario. En países europeos hay experiencias en este sentido de Alemania, Bélgica, los Países Bajos y Suiza. Israel también tiene un mecanismo de fondos de solidaridad.
} 
es la tónica de los sistemas de seguridad social en la mayoría de los países de la región), excluyen a la población sin capacidad contributiva o a los trabajadores independientes, los que son cobijados principalmente por la red de prestadores del sector público y, en menor medida, por el sector privado. Si se desea universalizar la cobertura poblacional del seguro es necesario abrir las fuentes de financiamiento más allá de las contribuciones laborales obligatorias y forzar las contribuciones de trabajadores independientes con capacidad contributiva. Además, el aporte de las personas que no tienen capacidad de contribuir debe provenir de impuestos generales. Esto permite generar mecanismos de solidaridad de ingresos entre contribuyentes y no contribuyentes a la seguridad social.

Dadas las limitaciones presupuestarias que enfrentan los gobiernos, es importante que las contribuciones obligatorias sean también una fuente de financiamiento de la solidaridad. En el caso chileno, por ejemplo, el grueso de las contribuciones para salud no aporta a la solidaridad de ingresos (sólo lo hace el $40 \%$ de cotizaciones que van al seguro público), debiendo el Estado obtener los recursos de otras fuentes. ${ }^{8}$ Cuando las contribuciones obligatorias no participan del financiamiento solidario, aumenta la carga fiscal que el Estado debe asumir. Y si las necesidades de financiamiento solidario son altas, pueden transformarse en una exigencia difícil de satisfacer por el presupuesto público.

Un tema no menor es entonces el de la capacidad contributiva de los afiliados al sistema. Como vimos en las secciones introductorias, la precariedad del mercado de trabajo de los países de la región, unida a la mayor volatilidad del ciclo económico, ha llevado a que se generen importantes lagunas contributivas. Esto implica, por una parte, que sectores significativos de la población pasen de una situación de aseguramiento a una de desprotección, con los consecuentes costos sociales. Por otra parte, la discontinuidad en el empleo se traduce en una baja densidad de las contribuciones que crea serios problemas de sustentabilidad financiera en el sistema de seguros. Por lo tanto, en un esquema de seguros sociales de riesgos es fundamental contar con mecanismos complementarios que aseguren la densidad de las contribuciones, como seguros de desempleo o seguros dedicados específicamente a cubrir las contribuciones en períodos de desempleo. De cualquier modo, estos seguros complementarios generan una demanda de recursos fiscales adicionales o de primas de seguros adicionales (Velásquez, 2003).

\footnotetext{
${ }^{8}$ En el caso chileno las contribuciones obligatorias a la seguridad social que se canalizan a través de los seguros privados son de riesgo individual y no hay mecanismos de solidaridad de ingreso.
}

\section{c) Beneficios garantizados y responsabilidades fis- cales}

Un aspecto que causa gran controversia política y técnica, pero que es central para el funcionamiento de un sistema de seguros y está estrechamente ligado a las necesidades de financiamiento, es la determinación del paquete de beneficios garantizados. Si bien esto involucra factores éticos, políticos, culturales, médicos y económicos, aquí nos centraremos en estos últimos.

Una vez que la sociedad fija un conjunto de prestaciones a las cuales todos los afiliados al seguro social tienen derecho a acceder y que es efectivamente exigible por las personas, queda automáticamente establecida una obligación financiera a lo largo del tiempo. Si el seguro social se financia con contribuciones y con aportes generales, la exigibilidad de los beneficios envuelve la generación de pasivos contingentes para el sector público. Esto es, al fijar un derecho social exigible, el Estado tiene la obligación de garantizar ese derecho, lo que equivale a la obligatoriedad de financiarlo en el tiempo.

Para financiar pasivos contingentes es preciso establecer reglas de financiamiento que garanticen la provisión de los beneficios ofrecidos y respeten la disciplina fiscal encaminada a cumplir con las metas que regulan el gasto público. A su vez, la capacidad de financiamiento de los pasivos contingentes se ve seriamente afectada por el ciclo económico. Una forma de enfrentar esta situación es mediante fondos de estabilización específicos, que acumulan recursos en tiempos de crecimiento económico y desacumulan en tiempos de recesión y que permiten independizar la disponibilidad de financiamiento de la coyuntura económica. Esta demanda de recursos públicos se suma a las demandas financieras para asegurar la densidad de contribución que requieren los sistemas de seguros.

La evolución en el tiempo de los pasivos contingentes también desempeña un papel fundamental en la sustentabilidad financiera del seguro social. Por ejemplo, las coberturas garantizadas deben ampliarse sobre la base de reglas y criterios que compatibilicen el aumento de beneficios con la necesidad de mantener las tendencias del gasto social dentro de posiciones fiscales sustentables en el tiempo, y deben fortalecer el componente actuarial de los sistemas de protección social. $^{9}$

\footnotetext{
${ }^{9}$ Hay que cuidar que, al definir los beneficios y las reglas de acceso a ellos, no se generen incentivos a la evasión. De lo contrario, se tendería a abultar el número de afiliados subsidiados y a elevar la carga para el fisco o los contribuyentes.
} 
d) Combinación público-privada, eficiencia y contención de costos

Los esquemas de seguros sociales administrados por aseguradoras públicas y privadas (y con una oferta de servicios constituida mediante una red de proveedores públicos y privados) deben diseñarse con cuidado. Una combinación mal concebida de esfuerzo público y privado en la gestión de la seguridad social origina ineficiencias en la gestión del financiamiento y la provisión de los servicios, lo que redunda en mayores presiones sobre el gasto público. Por eso, la organización industrial del sector desempeña un papel preponderante en cualquier diseño de reforma.

Las experiencias de reformas dentro y fuera de América Latina señalan que para incorporar adecuadamente al sector privado en el mercado de servicios de salud se necesita una fuerte capacidad regulatoria. Las fallas de mercado que se presentan en el ámbito del financiamiento y de la provisión hacen que la participación privada, en un mercado desregulado o insuficientemente regulado, lleve a pérdidas de eficiencia y equidad. En lo que toca al financiamiento, el problema principal para la equidad y la eficiencia es la posibilidad de que se incentive a las aseguradoras a efectuar una selección de riesgos (un "descreme")

La experiencia chilena permite ilustrar este punto. ${ }^{10}$ Las aseguradoras privadas (ISAPRES) se llevan cerca de un $60 \%$ de las cotizaciones obligatorias a la seguridad social en salud. Sin embargo, sólo el $25 \%$ de la población es atendida por estas instituciones, siendo el sector público responsable por el resto. Al observar la evolución por edad y sexo, se aprecia que en el sector público tiende a concentrarse la mayoría de la población, los más pobres y los más viejos, mientras que el sector ISAPRE cubre a los más jóvenes, sanos y de mayores ingresos (cuadros 8 y 9).

Como se ve, la combinación público-privada chilena concentra la cobertura de los peores riesgos económicos y de salud en manos del sector público, lo que redunda en un aumento de los requerimientos financieros de este sector. Lo anterior se contradice con el hecho de que la mayoría de las contribuciones obligatorias son destinadas al sistema ISAPRES, restando recursos financieros al fisco. Esto ha hecho que el Estado enfrente una creciente demanda de servicios de salud, con el consiguiente aumento de su carga financiera. A su vez, esta situación se ha visto agravada por una menor contribución al financiamiento solidario de la seguridad social que hace la población de mayores ingresos y por la existencia de subsidios que el Estado otorga, implícita o explícitamente, a la participación privada en salud.

Las demandas de mayores recursos financieros por parte del sector salud también se pueden atenuar de manera significativa mediante una mayor eficiencia que se materialice en una mejor gestión de los recursos y en la contención de costos en la provisión de los servicios. Para ello, es importante mejorar la gestión de los hospitales públicos y los mecanismos de asignación de recursos financieros a los proveedores

CUADRO 8

Chile: Fuentes de financiamiento del sector salud, 2000

\begin{tabular}{lrrr}
\hline Fuentes & \multicolumn{2}{c}{ Total } \\
\cline { 2 - 4 } & En miles de millones de pesos & En miles de millones de dólares & En \% \\
\hline Aporte fiscal & 613221 & 1048 & 21,0 \\
Aporte municipal & 38391 & 66 & 1,3 \\
Aporte empresas & 184311 & 315 & 6,3 \\
Cotizaciones & 1087216 & 1858 & 37,2 \\
Públicas & 444937 & 761 & 15,2 \\
Privadas & 642279 & 1098 & 32,0 \\
Gasto de bolsillo & 935923 & 540 & 10,8 \\
Copagos & 315855 & 493 & 9,9 \\
Farmacia & 288219 & 567 & 11,4 \\
Directo & 331849 & 106 & 2,1 \\
Otros & 62522 & 4933 & 100,0 \\
Totales & 2921584 & \\
\hline
\end{tabular}

Fuente: Datos del Ministerio de Salud de Chile.

\footnotetext{
${ }^{10}$ Esto no implica que el modelo chileno sea el único en la región que adolece de problemas de equidad y eficiencia, pero dada la
}

insuficiente regulación de la actual combinación público-privada es un muy buen ejemplo para observar los fenómenos de descreme. 
Chile: Distribución de la población en el sistema público de salud e instituciones de salud previsional (ISAPRES), por edades y por quintiles de hogares, 2000

\begin{tabular}{|c|c|c|c|c|c|c|c|c|c|c|c|c|c|c|c|}
\hline \multirow[t]{2}{*}{ Edades } & \multicolumn{3}{|c|}{ Quintil 1} & \multicolumn{3}{|c|}{ Quintil 2} & \multicolumn{3}{|c|}{ Quintil 3} & \multicolumn{3}{|c|}{ Quintil 4} & \multicolumn{3}{|c|}{ Quintil 5} \\
\hline & $\begin{array}{l}\text { Sistema } \\
\text { público }\end{array}$ & ISAPRES & Resto & $\begin{array}{l}\text { Sistema } \\
\text { público }\end{array}$ & ISAPRES & Resto & $\begin{array}{l}\text { Sistema } \\
\text { público }\end{array}$ & ISAPRES & Resto & $\begin{array}{l}\text { Sistema } \\
\text { público }\end{array}$ & ISAPRES & Resto & $\begin{array}{l}\text { Sistema } \\
\text { público }\end{array}$ & ISAPRES & Resto \\
\hline $00-20$ & 85,4 & 5,5 & 9,1 & 69,9 & 16,6 & 13,5 & 54,4 & 28,0 & 17,6 & 36,6 & 42,7 & 20,7 & 19,1 & 66,1 & 14,8 \\
\hline $21-50$ & 81,8 & 6,1 & 2,1 & 67,6 & 16,4 & 16,1 & 54,4 & 26,6 & 19,1 & 37,9 & 40,4 & 21,7 & 21,8 & 60,1 & 18,1 \\
\hline $51-64$ & 87,3 & 2,9 & 9,8 & 81,8 & 6,0 & 12,3 & 72,4 & 12,1 & 15,5 & 59,6 & 20,3 & 20,1 & 37,1 & 39,8 & 23,2 \\
\hline 65 y más & 89,5 & 0,8 & 9,7 & 91,1 & 1,1 & 7,8 & 89,4 & 1,6 & 9,0 & 79,4 & 5,9 & 14,8 & 55,5 & 21,8 & 22,7 \\
\hline Total & 84,2 & 5,4 & 10,4 & 71,2 & 14,6 & 14,2 & 59,5 & 23,3 & 17,3 & 44,3 & 35,2 & 20,5 & 26,5 & 55,2 & 18,3 \\
\hline
\end{tabular}

Fuente: Titelman (2000).

CUADRO 10

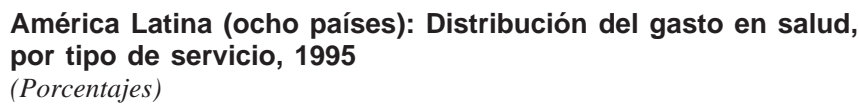

\begin{tabular}{|c|c|c|c|c|}
\hline País & Atención preventiva & Atención curativa & Administración & Otros rubros \\
\hline Bolivia & 2,8 & 61,8 & 10,4 & 25,0 \\
\hline Ecuador & 2,3 & 83,4 & 5,5 & 8,8 \\
\hline El Salvador & 7,8 & 71,4 & 8,2 & 12,6 \\
\hline Guatemala & 4,0 & 77,6 & 10,5 & 7,9 \\
\hline México & 9,0 & 80,0 & 3,0 & 8,0 \\
\hline Nicaragua & 17,5 & 75,6 & 6,3 & 0,6 \\
\hline Perú & 5,6 & 64,6 & 6,8 & 23,0 \\
\hline Rep. Dominicana & 7,4 & 67,0 & 15,5 & 10,1 \\
\hline Promedio & 7,0 & 72,6 & 8,3 & 12,1 \\
\hline
\end{tabular}

Fuente: Molina, Pinto y otros (2000), sobre la base de estudios de cuentas nacionales. Colaboración de la Organización Panamericana de la Salud/United States Agency for Internacional Development/Partnerships for Health Reform.

(presupuestos prospectivos y pagos asociados a prestaciones) e introducir cambios en el modelo de atención. En la región el grueso del gasto se da en acciones curativas más que preventivas (cuadro 10). Una de las vías más eficaces para contener los costos es fortalecer la prevención, para lo cual es preciso mejorar las redes de atención primaria.

\section{Reformas a los sistemas de pensiones}

\section{a) Organización del ahorro para el retiro}

Las reformas estructurales a los sistemas de pensiones ${ }^{11}$ han introducido importantes cambios en la

\footnotetext{
${ }^{11}$ Las reformas no estructurales a los sistemas de pensiones mejoran la solvencia del sistema público de pensiones para preservarlo y modifican la estructura de beneficios para adaptarla a las capacidades contributivas de sus afiliados. Entre otras medidas, estas reformas han variado las reglas de indexación, elevado las edades de
}

forma de relacionar los beneficios con las contribuciones. La mayoría de las reformas incluyen en mayor o menor grado esquemas ("pilares") de capitalización individual. ${ }^{12} \mathrm{E}$ pilar de capitalización individual puede complementar o sustituir al pilar de reparto. En

retiro, reducido la tasa de reemplazo, exigido condiciones más estrictas para acceder a pensiones de invalidez y sobrevivencia y a pensiones no contributivas, eliminado o reducido las pensiones de gracia o especiales de los funcionarios públicos, y aumentado los años de contribución requeridos para tener derecho a una pensión (Mesa-Lago, 1999).

12 Estos operan como cuentas de ahorro individuales cuyos beneficios se definen a partir de las contribuciones efectuadas, que son fijas y se capitalizan en cuentas individuales. Dada la esperanza de vida de la población, el valor de la anualidad se calcula a partir del valor capitalizado por el afiliado hasta la edad de retiro. En el sistema de reparto, los beneficios eran definidos y las contribuciones podían variar para ajustarlas a cálculos actuariales; las contribuciones se utilizaban para financiar los beneficios definidos de los afiliados, sin guardar una relación con los aportes y permitiendo subsidios cruzados 
la región, diversas experiencias combinan los nuevos pilares de capitalización plena individual y los antiguos pilares de reparto. Hay sistemas sustitutivos que cierran el sistema público y lo sustituyen por uno de capitalización plena individual (Chile, 1979-1981; México, 1995; Bolivia, 1996; El Salvador, 1996). Hay sistemas mixtos que incorporan un pilar de capitalización plena individual como parte integrante de un pilar público reformado (Argentina, 1993; Uruguay, 1995). Y hay sistemas paralelos que establecen un pilar de capitalización plena individual como optativo y paralelo al pilar público reformado (Perú, 1992; Colombia, 1993).

La forma de estructurar el financiamiento y el cálculo de los beneficios de los sistemas de pensiones en cada una de estas reformas no es neutra desde la perspectiva fiscal. Al cambiar la forma de relacionar los beneficios con las contribuciones y limitar la capacidad de aplicar subsidios cruzados entre contribuyentes (dejando al Estado el financiamiento de la función distributiva del sistema), las reformas afectan las responsabilidades fiscales.

\section{b) Costos de la transición}

El Estado debe responsabilizarse por los costos de la transición de un pilar a otro (en términos de los derechos adquiridos en contratos anteriores), que resultan de transformar las contribuciones a los sistemas públicos de reparto en aportes a cuentas de ahorro individual.

Este costo depende de los pasivos contingentes asociados a la fuerza de trabajo actual y en retiro, por concepto tanto de las cotizaciones realizadas al sistema antiguo como de los beneficios ya adquiridos (Uthoff y Bravo, 1999; CEPAL, 1998). Su magnitud puede estimarse en la forma de una deuda equivalente al valor presente del flujo futuro de beneficios a que tienen derecho las personas actualmente retiradas, así como el valor presente del flujo futuro de beneficios a que tienen derecho aquellos actualmente activos pero que han contribuido al sistema antiguo. La amortización de esta deuda requiere de complejos cálculos actuariales pero se materializa en una demanda de recursos fiscales que, si no tiene una contrapartida de financiamiento fiscal, viene a engrosar el déficit previsional. En el caso chileno esta deuda se financió en parte con ahorro fiscal primario y en parte con la emisión de bonos de reconocimiento. La forma y el momento en que se financia esta deuda depende del diseño de la transición de un sistema a otro. Las autoridades deben abordar las responsabilidades fiscales de la transición desde la perspectiva tanto de la reasignación de los gastos, como de la captación de mayores ingresos.
La experiencia chilena tras más de 20 años de reforma en que se ha ido sustituyendo un sistema de reparto por otro de capitalización individual es ilustrativa al respecto. El sistema reformado de pensiones se ha sustentado en un aumento medio del déficit previsional del orden de 2,0\% del PIB durante los primeros 20 años (Arenas de Mesa, 1999). Este déficit previsional (gráfico 2) se descompone en i) déficit operacional, que refleja el pago de los derechos de las personas ya retiradas; ii) amortización de los bonos de reconocimiento, que cubre los derechos de los que habiendo sido activos participaron del sistema anterior; iii) pagos a los sistemas de pensiones de las fuerzas armadas, y iv) beneficios sociales garantizados de protección a quienes llegan a la tercera edad en condiciones de indigencia (pensiones asistenciales) y a quienes, habiendo participado del sistema, no han podido acumular lo suficiente para lograr un beneficio socialmente aceptable (pensiones mínimas).

La magnitud de la deuda previsional que debe hacerse explícita al sustituir totalmente un pilar de reparto por uno de capitalización puede ser muy elevada, dependiendo de factores demográficos, de las características de la cobertura y condiciones de elegibilidad de los sistemas que son sustituidos, de los beneficios garantizadoss que se establezcan y del grado en que se reemplacen activos sin derechos de propiedad por activos con derechos de propiedad (Valdés, 2002). La parte que se hace explícita y que se traduce en demandas sobre el fisco como los ilustrados para Chile en el gráfico 2, depende también de la estrategia utilizada para abordar la reforma. Es posible que, previo a la reforma que incorpora los pilares de capitalización individual y para evitar costos operacionales y bonos de reconocimiento muy elevados, se tomen medidas como las siguientes: i) efectuar cambios en las reglas sobre beneficios y en las condiciones para acceder a ellos; ii) introducir sólo parcialmente un pilar de capitalización plena individual y minimizar los incentivos para trasladarse al nuevo pilar; iii) o, como en otras experiencias, incluir, en calidad de pasos intermedios de transición, criterios de contribuciones definidas y capitalización nocional de los sistemas de reparto. ${ }^{13}$

En la mayoría de las reformas ha habido dificultades para ajustar las demandas adicionales de recursos fiscales. Por ejemplo, en Argentina el gobierno debió echar pie atrás en la indexación de la prestación compensatoria (aquella que se daba por los derechos

13 Véase Holzmann, 1997; CEPAL, 1998; Carvalho y Paiva, 2000; Fox y Palmer, 2001. 


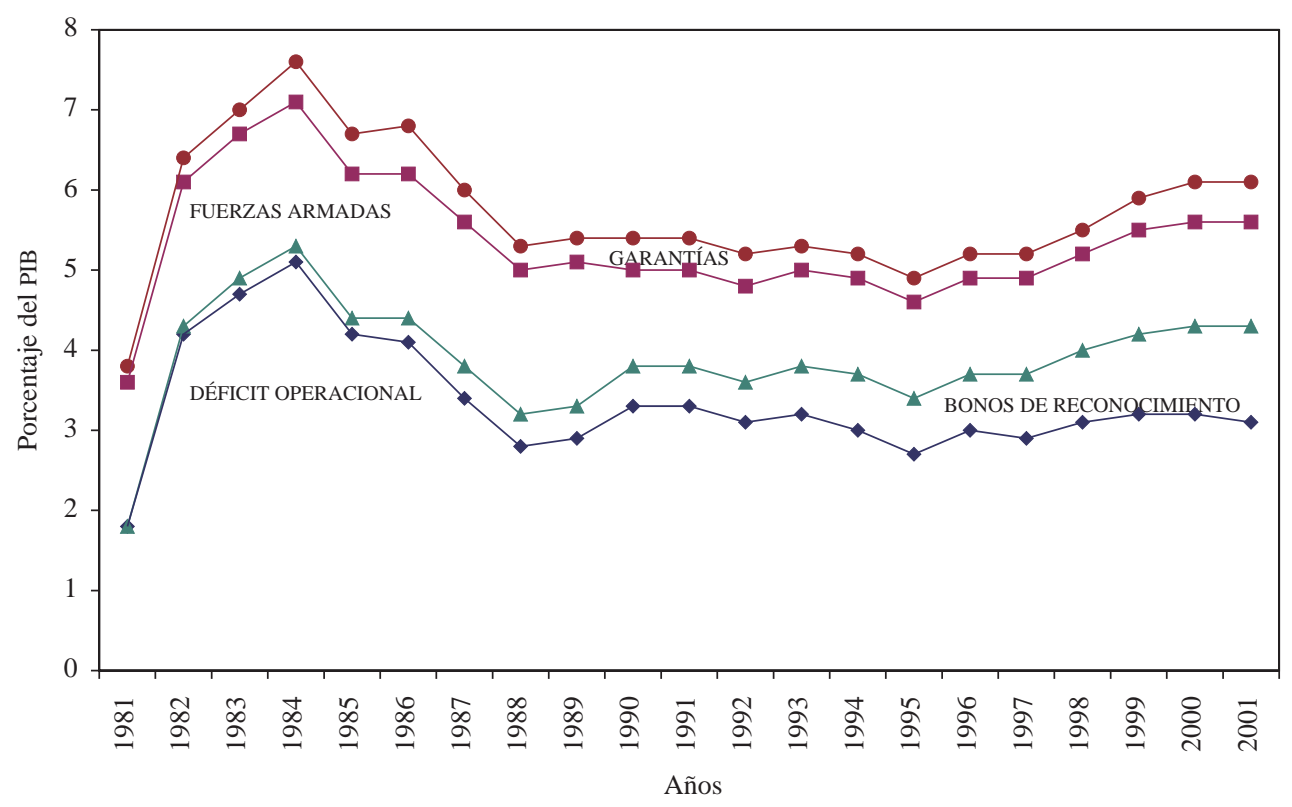

Fuente: Arenas de Mesa, 1999.

adquiridos a través de contribuciones al sistema anterior), y también respecto al aporte medio previsional obligatorio (AMPO) que la ley estableció como base para el cálculo de las pensiones compensatorias. En Bolivia, no se pudo cubrir el beneficio universal a los mayores de 65 años contemplado en el bono solidario (BONOSOL); aunque se amplió su beneficio a todos los mayores de 50 años, su valor se redujo de 250 a 90 dólares. En Chile, los montos de las pensiones mínimas son objeto de amplio debate, dado su impacto sobre el gasto fiscal; como una forma de controlar el gasto generado por las pensiones asistenciales (PASIS), éstas se ofrecen en función de cupos que establecen el número máximo que podrá otorgarse cada año (Gana, 2002).

\section{c) Efectos sobre el presupuesto fiscal}

El financiamiento solidario surge para proteger a quienes, por su historial contributivo, no pueden generar sus propias pensiones. La mayor vulnerabilidad actual de los trabajadores ante el desempleo, la rotación laboral y la incidencia del empleo informal y precario, hacen que cada vez sean menos los que aportan a los sistemas contributivos y que la densidad de las contribuciones sea baja. La forma de financiar las pensiones de las personas que no logran generar ahorros propios depende de fuentes de ingresos como subsidios cruzados y/o impuestos generales.
La posibilidad de materializar la solidaridad a través de las contribuciones disminuye al incorporar un pilar de capitalización plena individual. En este pilar, que está siempre en equilibrio actuarial, los beneficios de un afiliado son equivalentes a sus contribuciones debidamente capitalizadas y no existen subsidios cruzados. Dentro de este esquema, los que ahorran lo suficiente quedan asegurados y los que ahorran insuficientemente quedan subasegurados. La aplicación del principio de equivalencia circunscrito al pilar de capitalización plena individual no es incompatible con la posibilidad de que dentro del sistema reformado aquellos con baja capacidad contributiva reciban subsidios cruzados desde aquellos con alta capacidad contributiva. Para ello, las reformas estructurales a los sistemas de pensiones deben incorporar un pilar redistributivo para cubrir a estos trabajadores mediante financiamiento solidario. Este pilar redistributivo puede financiarse con mayores aportes fiscales y eventuales contribuciones. El problema fundamental de tal combinación de pilares es que, si se proveen beneficios mínimos y/o asistenciales en forma extremadamente generosa, no habrá incentivos para que los afilados permanezcan en los pilares contributivos más allá del tiempo necesario para acceder a los beneficios garantizados. Es indispensable, por lo tanto, corregir tales distorsiones. 
Beneficio como porcentaje del

salario medio de la economía

Población con derecho a beneficios garantizados como porcentaje de la $P E A^{b}$

\section{Retirados}

Futuras generaciones

Total

Amortización de la deuda (déficit fiscal)
15

\begin{tabular}{rrr}
\hline & & \\
35 & \multicolumn{1}{c}{45} & 55 \\
\hline 5,2 & 6,7 & 8,1 \\
30,4 & 39,1 & 47,8 \\
35,6 & 45,8 & 56,9 \\
& & \\
0,89 & 1,15 & 1,42
\end{tabular}

20

$\overline{-}$

\begin{tabular}{rrr}
35 & 45 & 55 \\
\hline 6,9 & 8,9 & 10,8 \\
40,5 & 52,1 & 63,7
\end{tabular}

$47,4 \quad 61,0 \quad 74,5$
30

\begin{tabular}{ccc}
35 & 45 & 55 \\
\hline 10,3 & 13,3 & 16,2 \\
60,8 & 78,2 & 95,6 \\
70,1 & 91,5 & 111,8
\end{tabular}

1,75

Fuente: Elaboración de los autores a partir de parámetros demográficos, cobertura, tasas de contribución y derechos exigibles estimados como tasa de reemplazo.

a Véanse detalles de la metodología en Uthoff y Bravo (1999).

b PEA: Población Económicamente Activa.

La cobertura que ha de tener un pilar solidario de reparto y la manera de financiarlo constituyen principales dilemas de las actuales reformas. Hay un amplio debate acerca de cuán exigibles son verdaderamente los derechos, sobre la capacidad de financiarlos y sobre los incentivos a la elusión y la evasión que puede generar la oferta de derechos no contributivos. Una forma de dimensionar el pilar solidario es simular un pilar distributivo de contribuciones definidas en favor de quienes son excluidos por el pilar de ahorro individual. Esto equivale a disponer en forma nocional de "cuentas de solidaridad" para cada ciudadano, con fines previsionales.

El cuadro 11 muestra para Chile simulaciones del valor presente por concepto de pagos de beneficios garantizados para los actuales retirados (fila 1), las futuras generaciones (fila 2) y el total (fila 3), así como el flujo de déficit fiscal que amortiza la deuda total en forma lineal (última fila). El método utiliza una tasa de descuento igual a la tasa de crecimiento de los salarios. La población con derecho a beneficios garantizados se expresa como porcentaje de la población económicamente activa (PEA): $35 \%, 45 \%$ y $55 \%$. Los beneficios se expresan en porcentajes del salario medio de la economía (15\%, $20 \%$ y 30\%). Dados los supuestos simplificadores, ${ }^{14}$ a cada uno de ellos corresponde una tasa de contribución de equilibrio actuarial.

\footnotetext{
${ }^{14}$ Se utilizan tres supuestos simplificadores: i) el porcentaje de la población elegible para recibir beneficios garantizados permanece
}

Bajo tales consideraciones, los déficit previsionales para pensiones asistenciales y mínimas de los actualmente retirados que hoy representan $0,4 \%$ del PIB (gráfico 2), aumentarán al 1,5\% del PIB una vez que se retiren las generaciones hoy activas. Cálculos de Arenas de Mesa (1999) sobre beneficios similares (pensión mínima) entregaron resultados parecidos. Los cálculos muestran que el porcentaje de la población con derecho a beneficios garantizados y la tasa de reemplazo y/o la tasa de contribución nocional con que se reconocen los derechos, influyen sensiblemente en la determinación de los pasivos contingentes.

Los cálculos de pasivos contingentes asociados a los beneficios garantizados dependen no sólo del monto de los beneficios, expresados, por ejemplo, como tasas de reemplazo de los salarios medios de la economía y la población cubierta. Responden también a factores estructurales asociados a la capacidad potencial de los afiliados para autofinanciarse una pensión, lo que se asocia en América Latina al grado de formalización de la economía, que en esta metodología se expresa por la participación de los asalariados en la PEA.

sin variaciones a lo largo del tiempo; ii) la población elegible que está en su etapa activa es acreedora a contribuciones solidarias desde la edad de 20 años hasta que se retira, a una tasa actuarialmente justa para financiar los beneficios garantizados; iii) la población elegible que ya está en edad de retiro recibe una pensión solidaria desde los 60 años, a una tasa de reemplazo actuarialmente equilibrada con el valor de los beneficios garantizados (Uthoff y Bravo, 1999). 


\begin{tabular}{|c|c|c|c|}
\hline & \multicolumn{3}{|c|}{$\begin{array}{c}\text { Estimado para el } 45 \% \text { de la PEA que pueden aceder a un beneficio, } \\
\text { a una tasa de reemplazo de } 20 \%^{\mathrm{a}}\end{array}$} \\
\hline & $\begin{array}{c}\text { Deuda con la generación actual } \\
(\% \text { del PIB })\end{array}$ & $\begin{array}{l}\text { Deuda con futuras generaciones } \\
(\% \text { del PIB })\end{array}$ & $\begin{array}{l}\text { Déficit fiscal que amortiza la deuda } \\
\text { (\% del PIB) }\end{array}$ \\
\hline Bolivia & 11,4 & 81,6 & 2,33 \\
\hline El Salvador & 9,5 & 63,2 & 1,82 \\
\hline México & 8,7 & 62,0 & 1,77 \\
\hline Chile & 8,9 & 52,1 & 1,53 \\
\hline
\end{tabular}

Fuente: Elaboración de los autores a partir de parámetros demográficos, cobertura, tasas de contribución y derechos exigibles estimados como tasa de reemplazo.

a Como porcentaje del salario medio.

También varían con factores demográficos como la relación de dependencia entre los mayores de 60 años y la población de 20 a 59 años y el promedio de años de vida esperada de los actuales mayores de 60. Puesto que estos factores varían mucho de un país a otro, el costo de beneficios similares puede diferir entre ellos (cuadro 12).

Reconocer derechos pensionales para aquellos que quedan subasegurados o no asegurados por un pilar de capitalización individual y cuantificar sus demandas en términos de pasivos contingentes implica transparentar la forma de complementar el pilar de capitalización individual y contribuciones definidas con un pilar de reparto y beneficios definidos, y requiere hacer explícitas las necesidades de financiamiento para cubrir a las personas subaseguradas o no aseguradas. Actualmente se debate si se debe financiar la solidaridad con un impuesto al trabajo (contribuciones), con impuestos generales o con una mezcla de ambos. De todas formas, la existencia de beneficios garantizados hace necesario un cuidadoso análisis del diseño de los nuevos sistemas, de modo que si incluyen pilares distributivos, éstos no generen incentivos a la evasión o elusión de las contribuciones. También debe velarse por que la forma de financiarlos no afecte el empleo, ya sea de manera directa al aumentar el costo de la contribuciones, o indirectamente al influir en los desequilibrios fiscales y la competitividad de las economías (отт, 2001b; Orszag y Stiglitz, 1999).

\section{d) Densidad de las contribuciones y pasivos contin- gentes}

En definitiva, la capacidad de un individuo para suavizar las fluctuaciones del consumo a lo largo del ciclo de vida dentro de la lógica del ahorro individual
CUADRO 13

América Latina (ocho países): Indicadores indirectos de la densidad de contribución (Porcentajes)

\begin{tabular}{|c|c|c|}
\hline Indicador de riesgo & $\begin{array}{l}\text { Diciembre } \\
\text { de } 2001\end{array}$ & $\begin{array}{l}\text { Diciembre } \\
\text { de } 2002\end{array}$ \\
\hline \multicolumn{3}{|c|}{$\begin{array}{l}\text { Densidad de contribución } \\
\text { afiliados/PEA }\end{array}$} \\
\hline Argentina & 54,3 & 55,4 \\
\hline Bolivia & 21,2 & 23,1 \\
\hline Chile & 108,1 & 111,8 \\
\hline Costa Rica & 53,8 & 69,3 \\
\hline El Salvador & 35,8 & 36,7 \\
\hline México & 63,8 & 71,9 \\
\hline Perú & 25,5 & 27,2 \\
\hline Uruguay & 38,9 & 41,4 \\
\hline \multicolumn{3}{|c|}{ Contribuyentes/afiliados } \\
\hline Argentina & 29,0 & 33,2 \\
\hline Bolivia & 47,0 & 46,9 \\
\hline Chile & 53,7 & 51,0 \\
\hline \multicolumn{3}{|l|}{ Costa Rica } \\
\hline El Salvador & 53,2 & 47,6 \\
\hline México & 44,7 & 41,7 \\
\hline Perú & 41,2 & 39,4 \\
\hline Uruguay & 53,2 & 45,1 \\
\hline \multicolumn{3}{|l|}{ Contribuyentes/PEA } \\
\hline Argentina & 15,7 & 18,4 \\
\hline Bolivia & 9,9 & 10,8 \\
\hline Chile & 58,0 & 57,0 \\
\hline \multicolumn{3}{|l|}{ Costa Rica } \\
\hline El Salvador & 19,0 & 17,4 \\
\hline México & 28,5 & 30,0 \\
\hline Perú & 10,5 & 10,7 \\
\hline Uruguay & 20,7 & 18,7 \\
\hline
\end{tabular}

Fuente: AIOS ( 2002).

requiere proyectar las densidades y montos de contribuciones mientras permanece afiliado al sistema 


\begin{tabular}{|c|c|c|c|c|}
\hline & \multicolumn{2}{|c|}{ Pobres } & \multirow[t]{2}{*}{ No pobres } & \multirow[t]{2}{*}{ Total } \\
\hline & Indigentes & No indigentes & & \\
\hline \multicolumn{5}{|l|}{1992} \\
\hline \multicolumn{5}{|l|}{ Sector informal } \\
\hline Servicio doméstico & 21,5 & 22,6 & 42,8 & 37,5 \\
\hline Otros & 21,1 & 25,9 & 26,2 & 25,9 \\
\hline Sector formal & 64,0 & 72,0 & 76,4 & 75,1 \\
\hline Total & 43,3 & 52,1 & 55,6 & 54,5 \\
\hline \multicolumn{5}{|l|}{2000} \\
\hline \multicolumn{5}{|l|}{ Sector informal } \\
\hline Servicio doméstico & 7,4 & 18,2 & 40,6 & 36,6 \\
\hline Otros & 9,3 & 18,9 & 28,2 & 26,6 \\
\hline Sector formal & 43,5 & 67,5 & 79,5 & 77,8 \\
\hline Total & 25,9 & 45,3 & 59,7 & 54,5 \\
\hline
\end{tabular}

Fuente: Tabulaciones de la CEPAL, con datos de la encuesta de Caracterización Socioeconómica Nacional (CASEN), Chile.

durante su vida activa. Esto determinará si accederá o no a beneficios satisfactorios. En los pilares de capitalización plena individual con contribuciones definidas la densidad de contribución de cada individuo determinará en gran medida si terminará su vida laboral como asegurado pleno, subasegurado o no asegurado, dependiendo de su propia capacidad de ahorro. Bajo la misma lógica, sin conocer de antemano la densidad de contribución será difícil precisar las contribuciones solidarias que el Estado debiera capitalizar (pasivos contingentes) para financiar la pensión garantizada en forma que sea equilibrada desde el punto de vista actuarial. ${ }^{15}$

La densidad de contribución se ve afectada por diversos riesgos, como los de invalidez y muerte, ${ }^{16} \mathrm{y}$ por la inestabilidad laboral que se manifiesta en variaciones del desempleo y la ocupación informal. En sociedades sin seguro de desempleo y con baja contribución de los trabajadores informales, ${ }^{17}$ los pasivos

\footnotetext{
${ }^{15}$ Los beneficios pueden ser diferentes, pues varían conforme al esfuerzo contributivo desde una pensión asistencial hasta una pensión mínima para quienes califican por su calidad de contribuyente elegible (Uthoff, 2002)

16 Además, muchos trabajadores se emplean por cuenta propia y optan por alternativas de ahorro más líquidas frente a eventuales contingencias (Coraggio, 2003).

${ }^{17}$ Debido a que las personas tienen diferentes necesidades a lo largo del ciclo de vida que compiten con el ahorro para la vejez.
}

contingentes son sensibles a las variaciones del ciclo económico. Utilizando indicadores de la Asociación Internacional de Organismos Supervisores de Fondos de Pensiones, el cuadro 13 muestra para varios países un porcentaje de afiliados que es bajo respecto de la PEA, lo que indica una cobertura también baja de los pilares de capitalización. ${ }^{18} \mathrm{~A}$ su vez, la reducida proporción de aportantes entre los afiliados es un indicador indirecto de que la densidad de contribución puede ser relativamente baja. La falta de instrumentos de mercado que puedan asegurar una alta densidad de contribución impide que, en especial, los sectores de bajos ingresos se beneficien de la protección social en ausencia de financiamiento solidario. Si bien hay nuevas iniciativas para impulsar seguros de desempleo, estas son aún incipientes y no toman en cuenta otras formas

\footnotetext{
${ }^{18}$ Los registros de afiliados y contribuyentes de los sistemas de pensiones dejan bastante que desear, por la posibilidad de doble contabilidad entre los primeros y porque entre los segundos no se mide la densidad de contribución. Este problema ha sido considerado de vital importancia por las autoridades chilenas. Se ha verificado que la densidad de contribución está lejos de la que se proyectó al instaurarse el sistema, y que presenta importantes diferencias por sexo y tramos de edad. En 2001, la densidad media de contribución de los afiliados al sistema de capitalización individual fue de $41 \%$, mientras que el promedio para los contribuyentes al sistema alcanzó a 59\%. Estos significa que en 12 meses los afiliados y contribuyentes de hecho sólo pagaron las contribuciones de 4,9 meses y de 7 meses, respectivamente (Gobierno de Chile, 2003).
} 
de ajuste de los mercados de trabajo, como el aumento de la actividad informal, en la cual la densidad de contribución es habitualmente baja.

En general, la evidencia indica que la contribución de un trabajador está estrechamente vinculada a la estructura del mercado de trabajo, con bastante independencia de los niveles de pobreza de los hogares

\section{IV}

\section{Conclusiones}

Las reformas a los sistemas de seguridad social envuelven la difícil tarea de conciliar derechos y necesidades con restricciones y carencias financieras. Las restricciones fiscales imponen un techo a la posibilidad de financiar las enormes demandas sociales de nuestros países. A su vez, el diseño e implementación de las reformas influyen significativamente en las demandas de recursos fiscales, en tanto afectan la eficiencia en la asignación y gestión de los recursos, las formas de financiar los mecanismos de solidaridad y los costos de transición.

En la demanda de servicios de seguridad social pesan factores que obedecen al ciclo económico y variables de carácter más estructural. Una de las principales vías por las que el ciclo económico influye en las fuentes de financiamiento y las demandas que se plantean a los sistemas de seguridad social es el mercado de trabajo. La poco favorable evolución de este último en los países de América Latina se ha traducido en mayores desafíos para las reformas a los sistemas de seguridad social.

En entornos económicos caracterizados por más incertidumbre y volatilidad, lo que se traduce en mayores riesgos sociales, las reformas a la seguridad social deben conciliar las funciones de aseguramiento y ahorro con las de redistribución y solidaridad. Esto es crucial si se quiere avanzar hacia la universalidad de la cobertura y de los beneficios.

En el caso del sector salud, los seguros sociales pasan a ser una forma eficiente de organizar el financiamiento. Para superar la actual segmentación poblacional entre diferentes subsistemas de protección social en materia de salud, es necesario independizar la pertenencia al seguro de la forma de inserción laboral. Esto es, el seguro debe cobijar a trabajadores dependientes e independientes y a la población sin capaci- a que pertenece. La condición de informal potencia los factores que le impiden alcanzar una alta densidad contributiva. La tasa de contribución en las actividades informales se mantiene relativamente estable, muy por debajo de las que se originan en las actividades formales. El cuadro 14 ilustra al respecto en relación con el caso chileno.

dad de contribución. Para ello es preciso establecer fondos de solidaridad financiados a partir de contribuciones y aportes fiscales. A medida que la gestión de los seguros sociales pueda incorporar a actores privados en la administración de los recursos, es fundamental evitar los problemas de selección de riesgos. Cuando participan administradoras privadas en el manejo del financiamiento y la provisión de servicios de la seguridad social es indispensable velar, mediante un buen marco regulatorio, por que estas entidades tengan iguales derechos y deberes que las administradoras públicas.

El avance hacia la cobertura universal en un contexto de aseguramiento social plantea una serie de demandas financieras al sector público. La definición de los beneficios cubiertos por el seguro, el monto de las pensiones mínimas y asistenciales, la garantía de la densidad de las contribuciones y el aporte al financiamiento solidario pueden significar importantes cargas financieras para el Estado.

A medida que los beneficios ofrecidos por los sistemas de seguridad social se transforman en derechos exigibles, pasan a constituir pasivos contingentes para el Estado, que deben ser financiados cualesquiera sean los vaivenes del ciclo económico. Una política macroeconómica que apoye a las políticas sociales no sólo debe preocuparse por suavizar los ciclos económicos, sino que debe, además, generar reglas de gasto fiscal que permitan un gasto público contracíclico. En este sentido, las reglas que tienden a vincular las metas fiscales con parámetros estructurales y no coyunturales son un buen apoyo de las políticas sociales.

Un tema no menor es el cálculo de los pasivos contingentes y su evolución en el tiempo. Estos se ven afectados por tres factores. En primer lugar, por el monto 
y volumen de los beneficios garantizados. En segundo lugar, por cambios significativos, a lo largo del ciclo económico, de la población con y sin capacidad de contribución; estos problemas asociados a la baja densidad de las contribuciones hacen que personas que apa- rentemente estaban aseguradas queden en condiciones de no aseguradas. En tercer lugar, por la forma en que se financia la solidaridad: si los aportes de trabajadores y empleadores no contribuyen a su financiamiento, el costo para el fisco tenderá a aumentar.

Bibliografía

AIOS (Asociación Internacional de Organismos Supervisores de Fondos de Pensiones) (2002): Boletín estadístico, № 8, Buenos Aires, diciembre.

Arenas de Mesa, A. (1999): Efectos fiscales del sistema de pensiones en Chile: proyección del déficit previsional: 1999-2037, artículo presentado en el seminario "Responsabilidades fiscales de los sistemas de pensiones" (CEPAL, Santiago de Chile, 2 y 3 de septiembre).

Arenas de Mesa, A. y J. Guzmán (2003): Política fiscal y protección social: sus vínculos en la experiencia chilena, serie Financiamiento del desarrollo, No 136, LC/L.1930-P, Santiago de Chile, CEPAL. Publicación de las Naciones Unidas, $\mathrm{N}^{\mathrm{o}}$ de venta: S.03.II.G.86.

Barr, N. (2000): Reforming Pensions: Myths, Truths, and Policy Choices, IMF Working Paper, No 139, Washington, D.C., agosto.

Buti, M., D. Franco y L.R. Pench (2000): Reconciling the Welfare State with Sound Public Finances and High Employment, documento de trabajo, Bruselas, Comisión Europea.

Carvalho, V. y S. Paiva (2000): Reforma previsional en Brasil. La nueva regla para el cálculo de los beneficios, serie Financiamiento del desarrollo, $N^{\circ}$ 97, LC/L.1386-P, Santiago de Chile, CEPAL. Publicación de las Naciones Unidas, $\mathrm{N}^{\circ}$ de venta: S.00.II.G.62.

CEPAL (Comisión Económica para América Latina y el Caribe) (1998): El pacto fiscal: fortalezas, debilidades, desafíos, serie Libros de la CEPAL, No 47, LC/G.1997/Rev.1-P, Santiago de Chile. Publicación de las Naciones Unidas, $\mathrm{N}^{\circ}$ de venta: S.98.II.G.5.

(2001a): Crecer con estabilidad. El financiamiento del desarrollo en el nuevo contexto internacional, Santafé de Bogotá, CEPAL/Alfaomega.

(2001b): Panorama social de América Latina, 2000-2001, LC/G.2138-P, Santiago de Chile. Publicación de las Naciones Unidas, $\mathrm{N}^{\mathbf{o}}$ de venta: S.01.II.G.141.

(2002a): Estudio económico de América Latina y el Caribe, 2001-2002, LC/G.2179-P, Santiago de Chile. Publicación de las Naciones Unidas, $\mathrm{N}^{\circ}$ de venta: S.02.II.G.02.

(2002b): Balance preliminar de las economías de América Latina y el Caribe, 2002, LC/G.2196-P, Santiago de Chile. Publicación de las Naciones Unidas, $\mathrm{N}^{\circ}$ de venta: S.02.II.G.126.

(2003): Proyecciones de América Latina y el Caribe, 2003, serie Estudios estadísticos y prospectivas, No 19 , LC/L.1886-P, Santiago de Chile, abril. Publicación de las Naciones Unidas, $\mathrm{N}^{\circ}$ de venta: S.03.II.G.52.

Coraggio, J.L. (2003): Sobrevivencia y otras estrategias en Latinoamérica y el Caribe: la perspectiva de lo local, presentación realizada en el Encuentro del Grupo Regional de Gestión de la Oficina Regional de las Américas y el Caribe, Fondo de las Naciones Unidas para la Infancia (UNICEF) (La Habana, Cuba, 10 de abril).

Fox, L. y E. Palmer (2001): Pension Reform in Europe in the 90's and Lessons for Latin America, serie Financiamiento del desarrollo, No 114, LC/L.1628-P, Santiago de Chile, CEPAL. Publicación de las Naciones Unidas, $\mathrm{N}^{\mathrm{o}}$ de venta: E.01.II.G.166.
Gana, P.A. (2002): Las pensiones no contributivas en Chile: pensiones asistenciales (PASIS), en F. Bertranou, C. Solorio y W. Van Ginneken (comps.), Pensiones no contributivas y asistenciales, Santiago de Chile, Organización Internacional del Trabajo (OIT).

Gobierno de Chile (2003): Observatorio laboral, Santiago de Chile, 9 de mayo.

Holzmann, R. (1997): On Economic Benefits and Fiscal Requirements of Moving from Unfunded to Funded Pensions, serie Financiamiento del desarrollo, $N^{\circ}$ 48, LC/L.1013, Santiago de Chile, CEPAL.

Londoño, J.L. y J. Frenk (1997): Pluralismo estructurado: hacia un modelo innovador para la reforma de los sistemas de salud en América Latina, Salud y gerencia, $\mathrm{N}^{\circ} 15$, Santafé de Bogotá, Pontificia Universidad Javeriana, julio-diciembre.

Mesa-Lago, C. (1999): La reforma estructural de pensiones en América Latina: tipología, comprobación de presupuestos y enseñanzas, Pensiones en América Latina. Dos décadas de reforma, segunda edición, Lima, Organización Internacional del Trabajo (OIT).

Molina, R., M. Pinto y otros (2000): Gasto y financiamiento en salud: situación y tendencias, Revista panamericana de salud públi$c a$, vol. 8, No 1-2, Washington, D.C., Organización Panamericana de la Salud (OPS), julio-agosto.

Naciones Unidas (2002): Protección social, Boletín sobre la erradicación de la pobreza, $\mathrm{N}^{\circ} 8$, Nueva York, División de Política Social y Desarrollo.

OIT (Organización Internacional del Trabajo) (2001a): Panorama laboral, 2001. América Latina y el Caribe, Lima, Oficina Regional de la OIT para América Latina y el Caribe.

(2001b): Seguridad social: temas, retos y perspectivas. Informe IV, Conferencia Internacional del Trabajo, $89^{\mathrm{a}}$ reunión, Ginebra, junio.

OMS (Organización Mundial de la Salud) (2000): Informe sobre la salud en el mundo, Washington, D.C.

ops/OMS (Organización Panamericana de las Salud/Organización Mundial de la Salud) (1998), La salud en las Américas, 1998, Washington, D.C

Orszag, P. y J. Stiglitz (1999): Rethinking pension reform: ten myths about social security systems, en R. Holzmann y J. Stiglitz (comps.), New Ideas about Old-Age Security, Washington, D.C., Banco Mundial, septiembre.

Rodrik, A. (2001): ¿Por qué hay tanta inseguridad económica en América Latina?, Revista de la CEPAL, No 73 , LC/G.2130-P, Santiago de Chile, abril.

(1998): Where has all the growth gone? External shocks, social conflict, and growth collapses, Journal of Economic Growth, $\mathrm{N}^{\circ} 4$, Boston, Kluwer Academic Publishers.

Suárez, R. y otros (1995): Gasto en salud y financiamiento. América Latina y el Caribe, Desafíos para la década de los noventa, Washington, D.C., Organización Panamericana de la Salud (OPS)/Organización Mundial de la Salud (OMS), inédito.

Titelman, D. (2000): Reformas al sistema de salud en Chile: desafíos pendientes, serie Financiamiento del desarrollo, $\mathrm{N}^{\circ} 104$ LC/L.1425-P, Santiago de Chile, CEPAL, septiembre. Publicación de las Naciones Unidas, $\mathrm{N}^{\circ}$ de venta: S.00.II.G.99. 
Titelman, D. y A. Uthoff (2000): El mercado de la salud y las reformas al financiamiento de los sistemas de salud, en D. Titelman y A. Uthoff (comps.), Ensayos sobre el financiamiento de la seguridad social en salud. Los casos de Estados Unidos, Canadá, Argentina, Chile, Colombia, Santiago de Chile, Fondo de Cultura Económica/CEPAL.

Tokman, V. (2003): Hacia una visión integrada para enfrentar la inestabilidad y el riesgo, serie Financiamiento del desarrollo, $\mathrm{N}^{\circ}$ 127, LC/L.1877-P, Santiago de Chile, CEPAL. Publicación de las Naciones Unidas, $\mathrm{N}^{\circ}$ de venta: S.03.II.G.44.

Uthoff, A. (2002): Mercados de trabajo y sistemas de pensiones, Revista de la CEPAL, No 78, LC/G.2187-P, Santiago de Chile, diciembre.

Uthoff, A. y J. Bravo (1999): Transitional fiscal costs and demographic factors in shifting from unfunded to funded pensions in Latin America, serie Financiamiento del desarrollo, $\mathrm{N}^{\circ} 88$,
LC/L.1264-P, Santiago de Chile, CEPAL. Publicación de las Naciones Unidas, $\mathrm{N}^{\circ}$ de venta: E.99.II.G.38.

Valdés Prieto, S. (2002): Políticas y mercados de pensiones, un texto universitario para América Latina, Santiago de Chile, Pontificia Universidad Católica de Chile.

Van de Ven, W. y R. Van Vliet (1992): How can we prevent cream skimming in a competitive health insurance market? The great challenge for the 90s, en P. Zweifel y H.E. Frech (comps.), Health Economics Worldwide, Amsterdam, Kluwer Academic Publishers.

Velásquez, M. (2003): Seguros de desempleo, objetivos, características y situación en América Latina, serie Financiamiento del desarrollo, N 133, LC/L.1917-P, Santiago de Chile, CEPAL. Publicación de las Naciones Unidas, $\mathrm{N}^{\circ}$ de venta: S.03.II.G.73.

White, J. (1995): Competing Solutions, Washington, D.C., The Brookings Institution. 